\title{
Livestock salmonellosis in the Irkutsk region
}

\author{
Aldar Batomunkuev ${ }^{1, *}$, Alexander Sukhinin ${ }^{2}$, Ivan Silkin $^{1}$, and Vyacheslav Tarasevich ${ }^{1}$ \\ ${ }^{1}$ Irkutsk State Agrarian University named after A.A. Ezhevsky, 664038 Molodezhny township, Irkutsk region, Russia \\ ${ }^{2}$ St. Petersburg state academy of veterinary medicine, 196084 St. Petersburg, Russia
}

\begin{abstract}
The analysis of the incidence of livestock (cattle and pigs) of salmonellosis in the territory of the Irkutsk region during 2004-2016 was carried out. It was found that the incidence rate of cattle was $5.4 \pm 0.62$ per 100 thousands livestock, pigs $-4.0 \pm 0.04 \%$. The dynamics of reducing of the incidence of pigs was identified. Negative rates of increase in the incidence of animals were revealed. The epizootic index was 1.0. Salmonella of nine species (Salmonella dublin, S.enteritidis, S.choleraesuis, S.typhimurium, S.london, S.lindi, S.wernigerode and S.othmarschen) in cattle and five species (S.choleraesuis, S.enteritidis, S.typhimurium, S.rochdale and S.arizonae) in pigs were identified as the causative agent of the infection. S.dublin was dominated at the etiology of salmonellosis in cattle $(75.1 \%)(\mathrm{p} \leq 0.05)$, S.choleraesuis - in pigs $(89.2 \pm 2.9 \%)(\mathrm{p} \leq 0.01)$. Salmonellosis in cattle was recorded in 11 districts of the Irkutsk region, in pigs - in nine districts.
\end{abstract}

\section{Introduction}

Salmonellosis, widespread in many countries of the world, is a serious threat to human health [1]. As a result of Salmonella infection, about 94 million cases of gastroenteritis in people are recorded annually in the world, and in hundreds of thousands of cases the disease is fatal [2]. In the United States alone, about 1.4 million cases of salmonellosis among the population are observed each year [3], while economic damage is \$ 2.5 billion [4]. According to the report of the European Food Safety Authority (EFSA) for 2014, salmonellosis is one of the most common zoonoses and foodborne toxic infections $[5,6]$. About $8 \%$ of all cases of human salmonellosis refer to direct contact with animals; $13 \%$ are related to environmental sources, $14 \%$ to travel; about $55 \%$ - with food products and about $9 \%$ - with direct transmission from person to person $[1,7]$. The relevance of salmonellosis is determined by the fact that at present about $20 \%$ of the world's population is employed in the livestock sector. Salmonella is widespread in herds of farm animals, mainly among those animals that are used by humans for food [6]. Cattle (cattle) play a primary role as a source of foodborne infection [7]. In Russia, salmonellosis of cattle (especially calves), pigs and sheep is registered in many regions $[8,9,10]$, making up $15-45 \%$ in different territories in the structure of the incidence of zoonoses in farm animals.

Currently, there is a wide list of salmonellosis pathogens (about 2400 serovars, of which 150 are diagnosed in Europe) [11]. The leading role in the etiological structure of animal salmonellosis belongs to Salmonella enteritidis $(35.9 \%)$, S. typhimurium (13.2\%), S. dublin (11.2\%), S. choleraesuis (10.1\%)
[6]. At the same time, S. typhimurium and S. enteritidis are, in epidemiological terms, the most relevant for humans. Serovars S. panama, S.infantis are also significant for humans. S. newport. S. agona, S. london and others [6]. A number of Salmonella serovars enter Russia with imported food and raw materials [12].

Salmonella serovars vary greatly in terms of host range. Most of them are adapted to a certain circle of owners. The adapted salmonella serovars in cattle include S. dublin [13], in pigs - S. chooleraesuis [11]. In lambs, the most common cause of abortion, stillbirth, and disease are Salmonella S. abortusovis [14; 15]. Pathogens such as S. typhimurium and S.enteritidis can cause diseases in a wide range of hosts [16, 17]. Salmonella S. typhimurium is often associated with the disease in many animal species [17].

Along with the dominant role of S.dublin, pathogens such as S.typhimurium S. enteritidis, S. choleraesuis, S typhimurium, S. abortusovis, S. london, S. anfo, S. lindi and others in the etiology of cattle salmonellosis [18]. As for sheep, other Salmonella serovars, including S. typhimurium, S.dublin, S.anatum and others, have also been described as causative agents of abortion [14, 16, 19]. According to O. Alvseike et al. (2002), S.diarizonae is another common sheep-adapted serovar (its prevalence in Norwegian sheep is about $12 \%$ ).

It should be emphasized that in the last $20-30$ years there has been a change in the spectrum of salmonella pathogens in various animal groups: against the background of a decrease in the proportion of dominant salmonella serovars, an increase in the significance of those pathogens that previously did not play a significant role in the etiology of this infection [11]. Due to the fact that the clinical form of salmonellosis, the severity is largely determined by the serovar of the pathogen, the

Corresponding author: aldar.batomunckuev@yandex.ru 
study of the etiological spectrum of the pathogens of salmonellosis in animals in the long term is of great practical importance [7].

The distribution of Salmonella serovars among farm animals varies greatly in time and differs between geographical regions, age groups, clinical manifestations, and production systems [7]. Moreover, salmonellosis is a major socio-economic problem for both developing and developed countries. The economic damage from salmonellosis is caused by both high mortality of young animals and loss of productivity, as well as the costs associated with treatment and infection control, which makes salmonellosis one of the most economically important diseases of both cattle and small ruminants [7]. The above indicates that measures aimed at combating this infection should be carried out on a global scale $[2,16]$.

\section{Materials and methods}

The study and analysis of the incidence of cattle and pigs salmonellosis in the Irkutsk region was carried out using materials from reporting forms of the Federal State Budgetary Institution "Irkutsk Interregional Veterinary Laboratory" (IMVL) according to the results of studies conducted in IMVL, as well as in Tulunskaya, UstUdinsk, Usolskaya, Bratsk , Nizhneudinsk, Cheremkhov, Kuitun and Kachug laboratories of stations for combating animal diseases (2004-2016). A total of 7851 studies were completed. The results were processed according to standard statistical methods [20]. The incidence rate was determined per 100,000 livestock $(\% 000)$.

The tendency (over the study period) of the incidence of salmonellosis was evaluated according to a parabola of the first degree and coefficient c. To identify the significance of this trend, the Pearson coefficient (r) was used. The differences were statistically significant at $p \leq 0.05$. The study of the tension of the epizootic situation of salmonellosis was carried out using the epizootic index (IE).

The conditional dominance scale was used to assess the degree of dominance of Salmonella of various species isolated from livestock. Four classes were used (absolute dominants, dominants, subdominants and rare salmonella) according to the proportion of bacteria of a certain species in the total number.

\section{Results and discussion}

It has been established that salmonellosis is a relevant disease in cattle and pigs in the Irkutsk region. This infection in livestock was recorded annually and was characterized by coverage of $30 \%$ of the administrative areas of the study area. In this case, the average longterm incidence rate of salmonellosis of cattle in 2004-2016 turned out to be at the level of $5.4 \pm 0.620 / 0000$, pigs $-4.0 \pm 0.04 \%$ / The incidence of cattle was characterized by variability without significant dynamics $(r=-0.06 ; \mathrm{p}>0.05)$.

The highest incidence of salmonellosis occurred in 2007. (9.40 / 0000). Since 2008 in 2013, there was a decrease in the incidence rate to 2.80 / 0000 in 2013. In recent years of observation in the study area, there has been a slight increase in the incidence rate of cattle salmonellosis; the indicators ranged from 6.00/0000 (2014) to 4.40 / 0000 (2016) (Fig. 1).

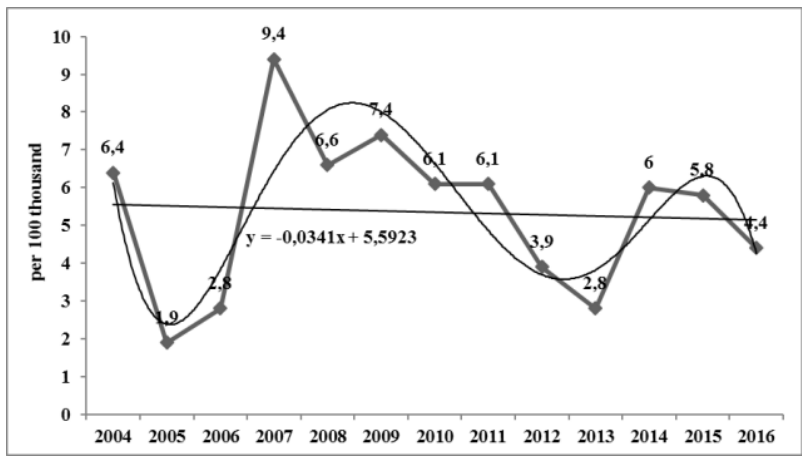

Fig. 1. Dynamics of the incidence of salmonella infection in cattle (Irkutsk region, 2004-2016)

Significant dynamics in reducing the incidence of pig salmonellosis was identified $(r=-0,585 ; \mathrm{p} \leq 0,05)$. The highest incidence rates of pigs were observed in 2004 $(10,5 \%$ \%000) and 2008. $(9,0 \% 0000)$; the lowest - at the end of the study period $(0,4 \% 0000)$ (Fig. 2$)$.

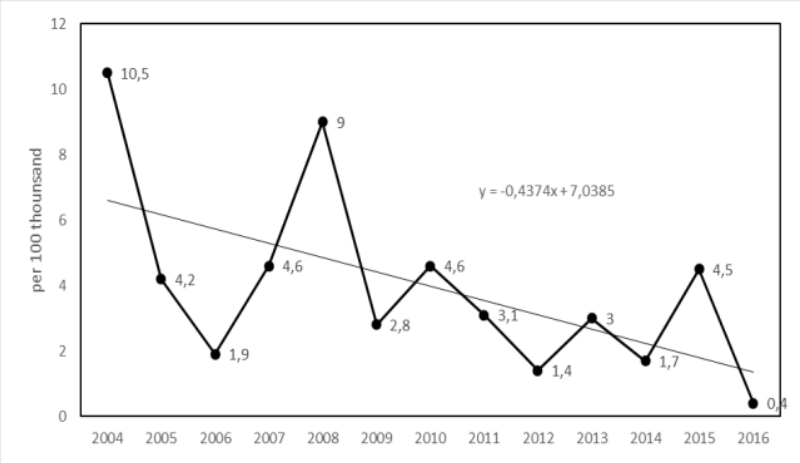

Fig. 2. Dynamics of the incidence of salmonella infection in pigs (Irkutsk region, 2004-2016)

The growth rate of the incidence of salmonellosis in cattle and pigs was negative. The rate of decline in the incidence of pigs was higher compared to that in cattle («-12.8\%» and «-0.7\%»).

The tension of the epizootic situation for cattle and pigs salmonellosis is reflected by an epizootic index of 1.0.

An analysis of the taxonomic spectrum of the etiological agents of salmonellosis revealed that salmonella isolated from cattle during 2004 - 2016 are represented by isolates of nine species: Salmonella dublin, S.enteritidis, S. choleraesuis, S. typhimurium, S. london, S. anfo, S. lindi, S. wernigerode, and S.othmarschen. Salmonella S.dublin $(75.1 \pm 3.0 \%)$ played a major role in the incidence of cattle. Their share was significantly $(p \leq 0.05)$ higher than the frequency of occurrence of salmonella of other species (fig. 3).

Salmonella of five species (S. choleraesuis, S.typhimurium, S. enteritidis, S. arizonae and S. rochdale) were isolated in pigs. Salmonella choleraesuis were dominated at the etiology of pig 
salmonellosis $(89.2 \pm 2.9 \%) \quad(p \leq 0,05)$. Salmonella of other species was much less often (fig. 4 ).

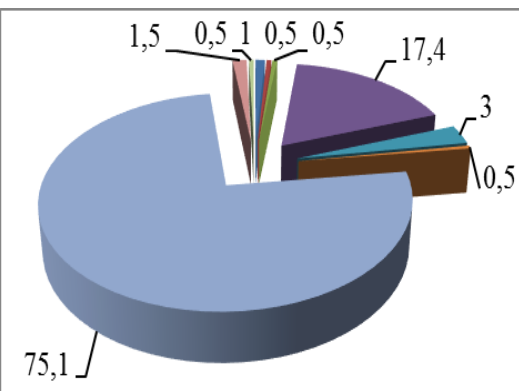

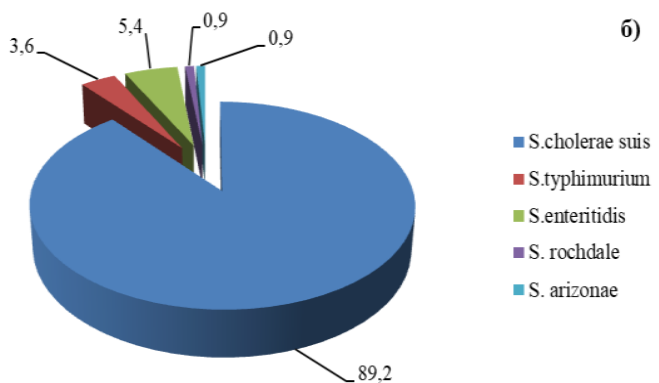

Fig. 4. Taxonomic spectrum of pig salmonellosis pathogens in the Irkutsk region, \% (2004-2016)

Fig. 3. Taxonomic spectrum of cattle salmonellosis pathogens in the Irkutsk region, \% (2004-2016)

Table 1. Assessment of the degree of dominance of Salmonella isolated from cattle (according to the conditional scale of dominance.

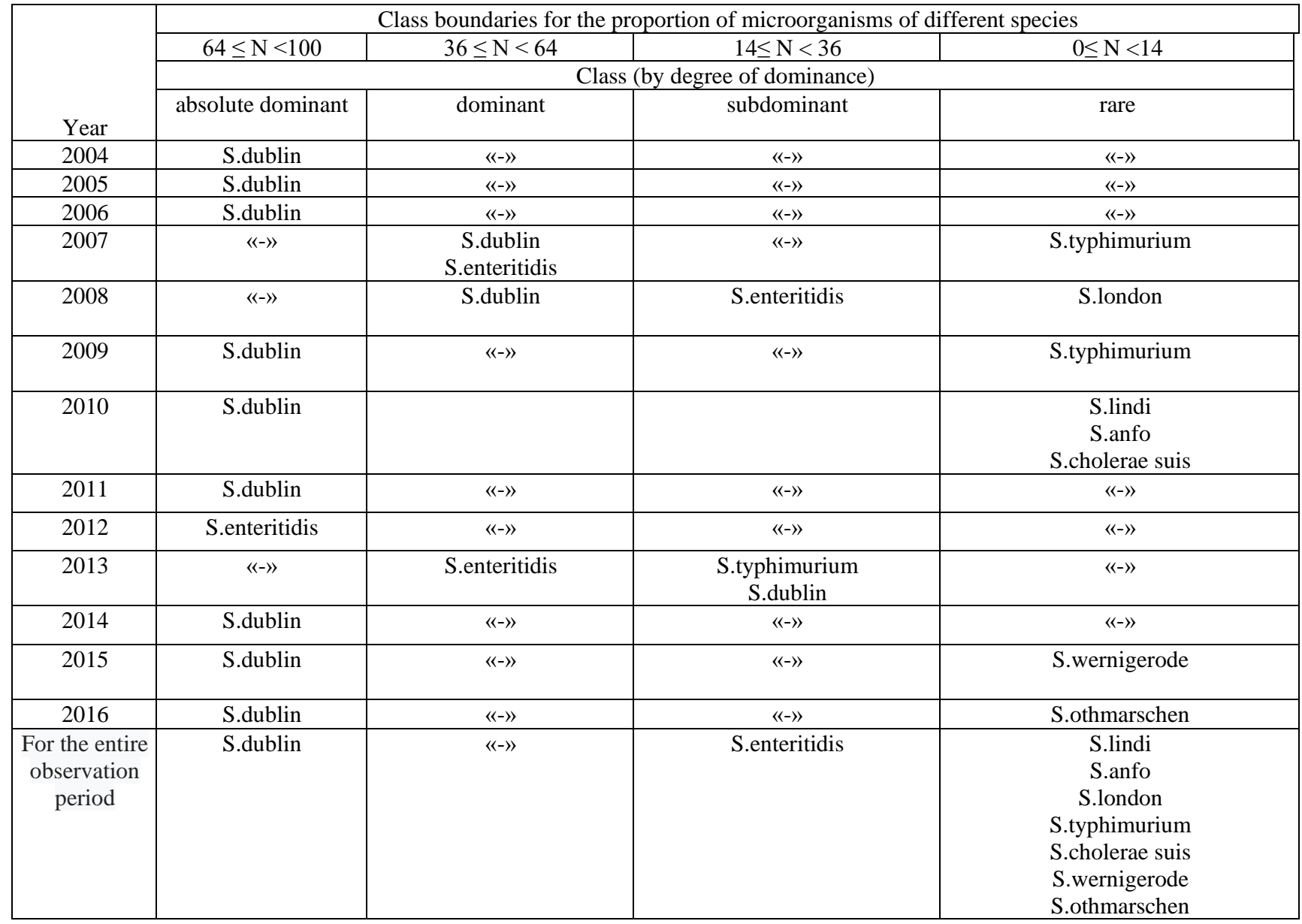

note.: «-»- were absent

The evaluation of the degree of dominance of Salmonella isolated from cattle, according to the conditional dominance scale, showed that S.dublin isolates constituted the class of absolute dominants (class boundaries in proportion from 64 to $100 \%$ ) for nine years (with a retrospection depth of 13 years). Salmonella S.enteritidis, according to the share of bacteria of this species in the total number, in some years belonged to the classes of absolute dominants (2012), dominants $(2007,2013)$ and subdominant (2008). In 2013, S. typhimurium strains were included in the subdominant class (class boundaries in a fraction of 14 to $36 \%$ ), and in other years they belonged to the class of rare species. Salmonella of all other species was included in the class of rare species (class boundaries in a fraction of 0 to $14 \%$ ) in the general structure of salmonellosis pathogens (table 1).

The results of the studies showed a slight change in the spectrum of salmonellosis pathogens during the observation period. Thus, strains of S.dublin, S. enteritidis and S typhimurium, as etiological agents of salmonellosis, were isolated during the entire study period. At the same time, strains S. london, S. anfo, S. lindi, S. choleraesuis were verified only in the first 
observation period (2004 - 2010), and in the subsequent $(2011-2016)$ isolates replaced them: S.wernigerode and S.othmarschen.

Salmonella choleraesuis were constituted at class of absolute dominants among Salmonella in pigs for 11 years. Salmonella enteritidis were entreated at the class of dominants in 2009; these isolates belonged to the class of subdominant and the class of rare species in other years $(2006,2014,2015)$. Salmonella typhimurium were part of the subdominant class during the all study period.

A study of the territorial distribution of salmonellosis in cattle showed its presence in 11 districts of the Irkutsk region (Tulunsky, Osinsky, Nizhneudinsky, Bohansky, Bratsky, Zalarinsky, Irkutsky, Kuytunsky, Usolsky, Ekhirit-Bulagatsky and Cheremkhovsky). At the same time, about half of all cases of salmonella infection in the studied group of animals were detected in the Cheremkhovsky district. Every tenth case of salmonellosis is diagnosed in the Usolsky, Kuitunsky and Ekhirit-Bulagat districts. In other administrative territories of the region, salmonellosis in cattle was recorded less frequently: this indicator varied from $0.5 \%$ to $3.0 \%$. Salmonellosis in pigs has been reported in nine districts (Tulunsky, Nizhneudinsky, Bohansky, Irkutsky, Usolsky, Ekhirit-Bulagatsky and Cheremkhovsky); more often the infection was diagnosed in pigs in the Nizhneudinsky, Usolsky and Tulunsky districts.

\section{Conclusion}

As a result of the studies, it was found that in 20042016 in the studied area, the incidence rate of salmonella infection of cattle was $5.4 \pm 0.62 \%$, pigs $-4.0 \pm 0.04$ $\%$. The highest rate was found in $2007(9.4 \% 0000)$. The recession took place in $2005(1.9 \% 0000)$. The incidence of pigs was characterized by a dynamics of decline: from $10.5 \%$ in 2004 to $0.4 \%$ in 2016 . The increase in the incidence rate was characterized by negative rates. The tension of the epizootic situation for this infection of the studied group of animals is evidenced by a high epizootic index (1.0). Nine species of Salmonella were verified as etiological agents in cattle, five species were verified in pigs. Salmonella Dublin were prevailed $(75.1 \pm 3.0 \%)(\mathrm{p} \leq 0.05)$ in the etiology of salmonellosis in cattle, S.choleraesuis in pigs $(89.2 \pm 2.9 \%)(p \leq 0.01)$, making up the class of absolute dominants. Salmonellosis in cattle was recorded in 11 regions of the study region. Most often in the Cheremkhovsky, EkhiritBulagat, Kuytun and Usolsky districts. Salmonellosis in pigs was detected in nine districts (mainly in the Lower Udinsky, Usolsky and Tulunsky districts).

\section{References}

1. Vargas-Galindo, Probabilistic inversion in priority setting of food borne pathogens, $\mathrm{PhD}$ dissertation thesis (2007)
2. S.E. Majowicz, J. Musto, E. Scallan et al., The global burden of nontyphoidal Salmonel gastroenteritis, Clin. Infect. Dis., 6(50) (2010)

3. F.W. Brenner, R.G. Villar, F.J. Angulo et al., Salmonella Nomenclature, J. of Clin. Microbiol., 7(38) (2000)

4. A.C. Voetsch, T.J. Van Gilder, F.J. Angulo et al., FoodNet estimate of the burden of illness caused by nontyphoidal Salmonella infections in the United States, Clin. Infect. Dis., 3(38) (2004)

5. A.V. Kulikovsky, A.N. Panin, E.V. Tarasenko, Distribution of some food zoonoses in the EU countries, Veter. Med., 6 (2015)

6. O.N. Vitkova, The study of the antibiotic resistance of salmonella isolated from animals and from food products of animal origin on the territory of the Russian Federation, Vet. of the Kuban, 2 (2015)

7. K. Hoelzer, Animal contact as a source of human non-typhoidal salmonellosis, Vet. Res., 1(42) (2011)

8. A.M. Ablov, A.A. Pliska, E.V. Anganova, A.S. Batomunkuev, Bacterial infections of animals in the territory of the Baikal region, J. of Infect. Pathol., 20 (2013)

9. B.F. Bessarabov, A.A. Vashutin, E.S. Voronin, Infectious diseases of animals (Moscow, 2007)

10. Yu.I. Barsukov, S.B. Bazarbaev, N.M. Vasilevsky, Nosological profile of infectious pathology of cattle in the Moscow region, Sci. notes of Kazan State Acad. of Vet. Med. named after N.E. Bauman, 214 (2013)

11. R.A. Kingsley, Host adaptation and the emergence of infectious disease: the Salmonella paradigm, Molec. Microbiol., 36 (2000)

12. S.V. Mezentsev, Salmonellosis - domestic or imported, Veter., 6 (2015)

13. LR. Nielsen, Salmonella Dublin infection in dairy cattle: risk factors for becoming a carrier, Prev. Vet. Med., 1-2(65) (2004)

14. Habrun, E. Listes, S. Spicic et al., An outbreak of Salmonella Abortusovis abortions in sheep in south Croatia, J. Vet. Med. B Infect. Dis. Vet. Public. Health., 53 (2006)

15. L. Belloy, L. Decrausaz, P. Boujon et al., Diagnosis by culture and PCR of Salmonella abortusovis infection under clinical conditions in aborting sheep in Switzerland, Vet. Microbiol., 138 (2009)

16. S. Uzzau, G.S. Leori, V. Petruzzi et al., Salmonella enteric serovar-host specificity does not correlate with the magnitude of intestinal invasion in sheep, Infect. Immun., 5(69) (2001)

17. W. Rabsch, Salmonella enterica Serotype Typhimurium and Its Host-Adapted Variants, Infect. Immun., 70 (2002)

18. Wray, Q.C. Wadsworth, D.W. Richards, A threeyear study of Salmonella Dublin infection in a closed dairy herd, Vet. Rec., 20(124) (1989) 
19. O. Alvseike, E. Skjerve, Prevalence of a Salmonella subspecies diarizonae in Norwegian sheep herds, Prev. Vet. Med., 3-4(52) (2002)
20. A.M. Ablov, A.S. Batomunkuev, E.V. Anganova, I.V. Meltzov, The use of statistical methods in the analysis of the epizootic situation of infectious diseases of animals and birds (2014) 